\title{
Commentary on 'Does Research Reduce Poverty? Assessing the Impacts of Policy-oriented Research in Agriculture'
}

\author{
Raghav Gaiha and Shantanu Mathur
}

\begin{abstract}
While entitlement protection is intrinsically a short-term task, building flexible and effective response mechanisms is a long-term one. So a more comprehensive research agenda is needed - especially in the context of countries/regions characterised by low and varying yields and with limited opportunities for trade with the rest of the world. $A$ case is, therefore, made for prioritisation of agricultural research, a pivotal role for the private sector and expansion of technology. Institutions matter a great deal, as ownership and access rights to natural resources (land, water) can have a significant impact on incentives to adopt sustainable agricultural options.
\end{abstract}

'Does Research Reduce Poverty? Assessing the Impacts of Policy-oriented Research in Agriculture' by Sumner et al. is an ambitious study of what we know about the impacts of agricultural research. It focuses on three areas of impact assessment of policy research:

- Whether a particular project has the desired impact on policy (auditing)

- What are the main factors affecting programme success and failure (learning)?

- What is the cost of achieving the outcomes compared to other interventions (costeffectiveness)?

These areas are subjected to a careful scrutiny through a detailed review of approaches that rely on case studies and econometric evidence in different regions of the developing world. We argue, however, that this study suffers from trying to cover a vast ground while losing focus on some key issues highlighted below. Our comments are brief and selective.

As the focus is on poverty impact of agricultural research, it is argued that a broader perspective is necessary. While entitlement protection is intrinsically a short-term task, building flexible and effective response mechanisms is a longterm one. So a more comprehensive research agenda is needed - especially in the context of countries/regions characterised by low and varying yields and with limited opportunities for trade with the rest of the world. From this perspective, a case is made for prioritisation of agricultural research, a pivotal role for the private sector and expansion of technology choice - appropriately contextualised to deal with intra-country location-specificity.

Recent reviews of the international agricultural research systems have drawn attention to the reconfiguration of the roles of the public and private sectors in promoting yield-enhancing and poverty-reducing technological change (Pingali and Traxler 2002; Timmer 2003; and Pender 2006). A selective summary of the important points is given below.

- There is a need for strategic leadership from the public sector in agricultural research (i.e. developing country NARS, the CGIAR Fund and Consortium, GFAR and donor agencies). This involves designing policies and channelling both public and private research into activities that would facilitate 
development of productivity-enhancing and poverty-reducing technologies. Specifically, the objective is to identify the crops, traits and technology choices that matter most to marginalised groups and agro-ecologically fragile regions and the markets they have access to.

- There is also a case for outsourcing many public research functions to the private sector, thereby creating new markets for strategic partnerships-based research, and reducing inefficiencies caused by poor public administration and management.

- No less important are incentive mechanisms to address public research priorities through private research extension in a manner that ensures more equitable distribution of benefits and costs across various stakeholders. ${ }^{1}$ Examples include public-private research partnerships, competitive research grants, and tax incentives.

- Finally, careful attention must be given to creating an enabling environment for private research in developing countries. The key elements include improvements in varietal registration procedures, bio-safety regulation processes, and intellectual property rights (IPR) enforcement at the national level; improvements in communications infrastructure; and harmonisation of regional and international regulations to create larger markets for private research investment.

Recent literature displays a shift of emphasis from static indicators of poverty to vulnerability to idiosyncratic and covariate shocks (e.g. Dercon 2005; Gaiha and Imai 2009; Gaiha et al. 2010). As an example of the latter, the rise in the frequency of droughts and the resulting devastation are viewed with considerable concern. Drought prevention is thus a major priority for agricultural research. A few remarks from this perspective are made below.

- Important progress has been made in developing drought-tolerant rice germplasm. Complementary crop management research for avoiding drought stress, better utilisation of available soil moisture and enhancing the ability of plants to recover rapidly from drought is likely to substantially enhance returns.

- Technologies must display greater flexibility in crop choice, and in the timing and quantity of various inputs. Gurrent rice priorities and general crop management practices are so rigid in drought-prone parts of India, for example, that they hardly change between normal years and early season drought. Rice technologies that allow for late transplanting in early season drought help protect yields better.

- However, in some cases, late season droughts are more common and disastrous. In addition to low or no harvest, farmers lose their investment in seeds, fertiliser and labour. The development of technologies that reduce the severity of the impact of a late season drought are thus a priority.

- Crop diversification is yet another droughtcoping option. In rainfed areas, for example, short duration rice varieties could facilitate planting of another crop using the residual moisture.

- In recent years, emphasis has shifted from large-scale irrigation that was a feature of the Green Revolution to small and minor irrigation schemes, and land use practices that generally enhance soil moisture and water retention. In China and Thailand, for example, the use of farm and community ponds is common. These small-scale schemes tend to be low cost and sufficiently responsive to the local needs. Similarly, watershed-based approaches in drought-prone areas in India provide opportunities for achieving long-term drought-proofing by improving the overall moisture retention within the watersheds (Pender 2006).

- Recent advances in meteorology have contributed to greater accuracy in forecasting droughts. Various indicators such as the Southern Oscillation Index (SOI) are now routinely employed in several countries to forecast droughts. However, a priority is to match the scientific advance with better preparedness to deal with droughts.

- Finally, institutions matter, and policy research has done much to reveal the impact of non-biophysical variables on technology change. For instance, ownership and access rights to natural resources (land, water, etc.) can have a significant impact on incentives to adopt sustainable agricultural options, while shifts in production options can change the household consumption basket and impinge on nutritional-status outcomes (Hazell and Haddad 2001). 
In brief, if agricultural research has fallen short of its potential impact on poverty, particularly when it is broadly interpreted to include vulnerability to shocks, solutions lie in

\section{Note}

1 As improved rice is self-pollinating, it offers limited profitability to private companies. This applies to wheat as well, but not to maize - hence the far greater investment in developing improved varieties of maize than rice or wheat. This constraint is overcome to

\section{References}

Dercon, S. (2005) 'Risk, Insurance and Poverty', in S. Dercon (ed.), Insurance Against Poverty, Oxford: Oxford University Press

Gaiha, R. and Imai, K. (2009) 'Measuring Vulnerability and Poverty: Estimates for Rural India', in W. Naudé, A.U. Santos-Paulino and M. McGillivray (eds), Vulnerability in Developing Countries, Tokyo: UNU Press

Gaiha, R.; Hill, K.; Mathur, S. and Kulkarni, Vani S. (2010) 'Devastating Droughts', revised version of a paper presented at the NBER conference, 'Climate Change: Past and Present', Cambridge, MA, May 2008 and May 2009

Hazell, P. and Haddad, L. (2001) Agricultural Research and Poverty Reduction, Food, Agriculture reprioritisation of agricultural research, a pivotal role to the private sector, and expansion of technological options in dealing with natural catastrophes such as droughts.

some extent by high-yielding hybrid rice varieties. Their offspring displays a high rate of sterility and genetic variation, making it impractical for farmers to use such seeds for planting. Hybrid rice was developed and heavily promoted by the government of China, and was widely adopted (Pender 2006).

and the Environment, Discussion Paper 34, Washington DC: International Food Policy Research Institute (IFPRI)

Pender, J. (2006) 'Agricultural Technology Choices for Poor Farmers in Less-Favoured Areas of South and East Asia', draft, Rome: International Fund for Agricultural Development (IFAD)

Pingali, P. and Traxler, G. (2002) 'Changing Locus of Agricultural Research: Will the Poor Benefit from Biotechnology and Privatisation Trends?', Food Policy 27

Timmer, C.P. (2003) 'Biotechnology and Food Systems in Developing Countries', The Journal of Nutrition 133.11 